\title{
Group Size and Age-sex Composition of Gaur (Bos gaurus) in Kuldhia Wildlife Sanctuary, Eastern Ghats, India
}

Sangram Parida* ${ }^{1 *}$ S.K. Sajan', S. Debata', G.C. Das' ${ }^{1}$, S.D. Rout' ${ }^{1}$, H.K. Sahu ${ }^{2}$

${ }^{1}$ P.G. Dept. of Wildlife \& Biodiversity Conservation, North Orissa University, Baripada, India

${ }^{2}$ P.G. Dept. of Zoology, North Orissa University, Baripada, India

Study Area: Kuldhia Wildlife Sanctuary,Eastern Ghats, India.

Coordinates: $21^{\circ} 20^{\prime} \mathrm{N}$ to $21^{\circ} 30^{\prime} \mathrm{N}$ (Lat.); $86^{\circ} 30^{\prime} \mathrm{E}$ to $86^{\circ} 45^{\prime} \mathrm{E}$ (Long.)

Key words: Bovine, Artiodactyla, Bos gaurus, Kuldhia WLS, Odisha

\section{Abstract}

The Gaur is under the vulnerable category on Red list and Schedule-I species as per Wildlife Protection Act (1972) in India. Till date, little information is available on group size and age-sex composition of Gaur from Kuldhia Wildlife Sanctuary. Thus, by keeping the same in mind an investigation of group size and age-sex composition of Gaur was carried out during January to June 2013 in Kuldhia Wildlife Sanctuary. In addition, the secondary sources of data from 2007-2013 were also collected from forest department. During investigation 26 direct sightings and 72 saltlick record from different part of the sanctuary was considered. A total of 14 group-sizes were recorded and the group size varied from one to eighteen individuals. Solitary male group constitute $27.55 \%$ $(\mathrm{n}=27)$, which is the dominant group size from other three group (Mixed, all male and all female). For age and sex composition, gaur mainly classif ied into four type's i.e. adult male, adult female, juvenile (sub adult male and female) and calf. Total 98 (saltlick and direct sighting data) sightings consisted 453 individuals of gaur in KWLS, out of which 27 sightings were of loners. All the loners were adult male and they were found apart from the groups. Adult male constitute $22.51 \%(\mathrm{n}=102)$ from the total number of gaur sighted.

*Corresponding Author: sangramparidao2@gmail.com 


\section{Introduction:}

Gaur (Bos gaurus) is commonly referred as the Indian bison and is the largest living bovine belongs to the order Artiodactyla. Due to habitat fragmentation and rapid declining of population it is place under vulnerable category on Red list (www.iucnredlist.org), listed in Appendix I of the Convention on International trade in Endangered Species of Wild Fauna and Flora (CITES) and including in Schedule-I species of Wildlife Protection Act (1972).

Gaur is distributed in Bangladesh, Bhutan, Cambodia, China, India, peninsular Malaysia, Burma, Nepal, Thailand and Vietnam (Datta et al., 1982; Grubb 2005). In India Gaur is distributed in more or less isolated patches, largely corresponding to the major mountain systems of the Western Ghats ranges, Central Indian highlands, South-western and North-Eastern Himalayas (Choudhury, 2002).

Group formation and age structure of a population is useful key for understanding dynamics of population growth of Gaur and estimating their life history parameters (Spillet, 1966; Stearns, 1992; Krause \& Ruxton 2002). Age structure of a population expressed as interrelated aspect of the distribution of the number of individuals in each age group reflects fecundity, mortality, reproductive status and population increase. Sex ratio is an indicator of the reproductive potentiality of a species. A high percentage of young as compared to adults generally indicates a fast growing or thriving population in contrast to a relatively smaller percentage of young that usually indicates a sluggish rate of population increase.

\section{Materials and methods:}

Study Area: Kuldhia Wildlife Sanctuary (KWLS) is situated in the district of Balasore. It is a part of the mega habitat comprising Similipal-Kuldhia-Hadgarh located on northern tip of the Eastern Ghats and linked with Similipal through Sukhupada hills and Nato hill ranges. A total of 3.9 percent area was found to possess very high plant richness followed by high $(21.2 \%)$, medium (42.1\%) and low (32.8\%) in the sanctuary were considering the rich on biological diversity. The sanctuary harbour mainly three types of forests, viz., Northern Tropical Semi Evergreen Forest, Peninsular (coastal) Sal Forest and Moist mixed Deciduous Forest (Champion \& Seth, 1968). The area of sanctuary is $272.75 \mathrm{sq} \mathrm{km}$ being covers with three major reserved forests namely Kuldhia, Tenda and Devgiri

R.F. besides some revenue forest along the fringe. In addition, some Cycus plants and few mangrove trees are also found at Gudikhola area. The Sanctuary is rich in complete biodiversity. Some of the noteworthy flora species are: Shorea robusta (Sal), Terminalia tomentosa (Asan), Pterocarpus marsupium (Bija), Annogeissus latifolia (Dhaura), Dalbergia latifolia (Pahadi sisoo), Diospyros embryopteris (Mankada kendu), Emblica officinalis (Amla) etc. with some bamboo Ambient Science (2015) http://www.caves.res.in/

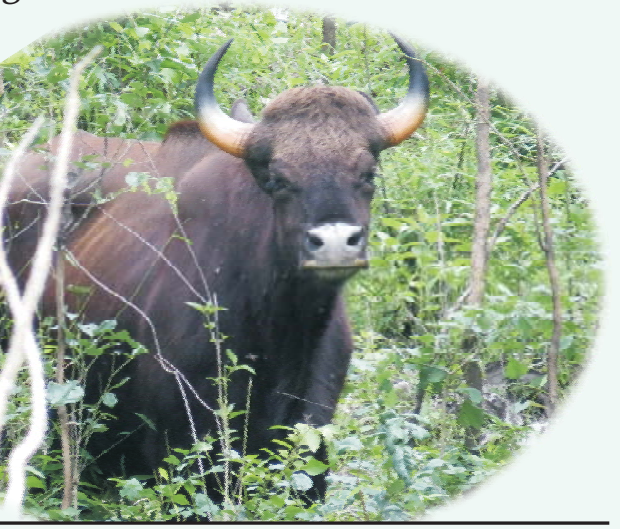

Vol.-02(2): p-26 
patches. The Sanctuary also harbours good numbers of Orchids, Cycas and verities of medicinal herb. Being a part of mega-habitat, the sanctuary boost of harboring the largest land animal like Elephant. The main faunal group in reptiles Ophiophagus hannah, Pytho molurus, in aves Anthracoceros coronatus, Bubulcus ibis, Halcyon smyrnensis, Perdix perdix, Passer domesticus, Oriolus oriolus and Cyanocitta cristata, among mammals Panthera pardus, Bos gaurus, Melursus ursinus, Axis axis, Muntiacus muntjak, Tragulus kanchil, Sus scrofa, Paradoxurus hermaphroditus, Manis crassicaudata, Ratufa indica etc.

Data Collection: The survey was carried out during January 2013 to June 2013. Each wildlife beats coming under the sanctuary was treated as one survey unit for collecting data regarding group size and age-sex composition of gaur. All the trails and roads present in the beat was covered by foot walk sampling in early morning and evening hours for direct sighting or evidences left by gaur. As gaur is known to be very shy towards human, so trekking was done with minimum noise inside the forest and whenever a group of gaur was sighted, observation have been done carefully with the help of binocular and each individual was tabulated carefully as per age and sex classes based on the criteria mentioned by Schaller (1967) and Krishnan (1972).

Adult Male: Sooty black in colour, enlarged dewlap, well diverged and fully converged tip of horn, prominent dorsal ridge and rotary movement of hump while walking.

Adult Female: Dark brown and closer to black in colour, non-prominent dewlap, less diverged but fully converged tip of horn, less prominent dorsal ridge.

Sub-adult Male: Black or brownish black in colour, prominent dewlap, the diverged horn about to converge.

Sub-adult Female: Brownish black in colour (blacker in thoracic portion and more brownish colour in the rump portion), dewlap absent and less diverged but not converged horn.

Calf: Golden brownish in colour and can pass through between the legs of its mother (less than three months old and approximately $1 \mathrm{~m}$ in height) in both sexes. No conspicuous white stockings.

However, the presence of the scrotum is the only morphological difference between the sexes, but is difficult to detect in free-ranging gaur of this age with appropriate modifications. While, age can be differentiate from their horn colour. As the age become older the white stockings in the horn is more and it was seen in a mature age of gaur that the horn is covered with fully white stockings. Proportion of different age and sex classes in the population was derived on the basis of all sightings during the study period. Apart from all the direct observations, 3-4 years before saltlick data were also collected as secondary data from forest department.

Results and Discussion:

Group Size: Total 26 direct sighting of present study and 72 saltlick record from different 
part of the sanctuary by forest department from 2007 to 2013 was considered for better understanding. Total 14 group sizes were recorded and the group sizes were seen to be varied between one individual to 18 individuals (Fig. 1). The mean group size of gaur in KWLS was 7.9 \pm 4.9 . Solitary male group constitute $27.55 \%(n=27)$ which was maximum group size followed by seven number constituted $13.27 \%(n=13)$, four number $12.24 \%(n=12)$, both five and six number had constituted 9.18\% $(n=9)$ eight number was constituted $8.16 \%(n=8)$, two numbers of gaur in a group observed seven times i.e. $7.14 \%$ $(n=7)$, three number of gaur was observed five time $5.10 \%$ $(n=5), 9$ and 11 number of gaur sighted only two times

$2.04 \%(n=2)$, finally $10,12,15$ and 18 number of group size

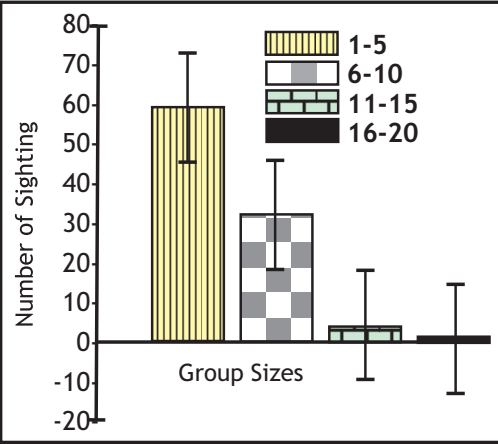
constitute $1.02(\mathrm{n}=1)$ respectively.

Group size range: A group size ranged from 1-5 individuals encountered maximum times i.e. 61.22\% ( $n=60)$ (Fig. 2), then the number contains 6-10 individuals in a group consists $33.67 \%(n=33), 11-15$ numbers of individuals in a group encountered only $4.08 \%(n=4)$, and finally $16-20$ numbers of gaur present in a group sighted only one times i.e. $1.02 \%(n=1)$ respectively. The study indicates that as the group sizes become smaller in number it increases the Figure 2. The group size ranges of Gaur number of sighting possibilities and as the group size became higher in number the number of sighting possibilities decreases.

Grouping characteristics of Gaur: After analysis all the saltlick and direct sighting data, group of gaur divided into four categories i.e. all male group, all female group, mixed group and solitary male group. All male groups constitute only male (more than one), all female group constitute only female (one or more than one), mixed group included male, female, juvenile and calf, and finally solitary male constitute only single male (apart from the group). The study revealed that sighting of mixed type group density was higher other then all types of groups. Mixed type of groups constituted $66.32 \%(n=65)$ followed by solitary male groups $27.55 \%(n=27)$, all male groups $3.06 \%(n=3)$ and all female groups $3.06 \%(n=3)$ respectively (Fig. 3). The study indicates that maximum time gaur prefers to remain in mixed group and maximum male gaur prefer to remain solitary but they came and join the group at the time of rut. After breeding season adult male leave the group and remain solitary till next breeding season. In mixed group, adult female gaur were more in

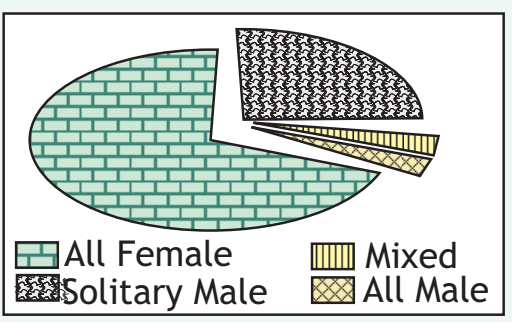

Figure 3. The pie-chat showing the percentage of group size of Gaur 
number followed by adult male, calf and juvenile. It was also observed that in all mixed types of group, there were presence of adult female gaur. In mixed group, number of female gaur vary from minimum one individuals to maximum 10 individuals, whereas male, calf and juveniles number vary from 1-3 individuals but it was seen that maximum times only one male was present in mixed groups.

Age sex composition: Total of 98 (saltlick and direct sighting data) sightings consists 453 individuals of gaur in

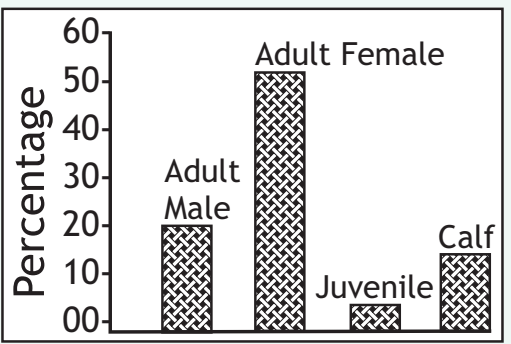

Figure 4. The proportion of Age-sex classes of Gaur ( $n=453)$.

KWLS, out of which 27 sightings were of loners. All the loners are adult male gaur and they remain apart from the groups. The gaur has been classif ied into four type's i.e. adult male, adult female, juvenile (Sub adult male and female) and calf. Adult females have the major proportion of the population i.e. $54.75 \%(n=248)$ followed by adult males $22.52 \%(n=102)$, calves $16.78 \%(n=76)$ and juveniles $5.96 \%(n=27)$ respectively (Fig. 4).

\section{Conclusion:}

The present study indicates that adult female number were more in comparison to adult male, Calf and Juvenile respectively. Sightings of highest number of gaur in a group was 18 and it was recorded from Jodachua saltlick in the year 2010 but during the study a group consisting of 15 numbers of gaur also sighted from Jodachua saltlick. According to Sankar et al., (2001) Gaur is a group living animal. Earlier it was established that the social organization of gaur herd consist of one or more related adult females and their offspring (Daniel et al., 1987; Sukumar, 1989; Schaller, 1967), but, our study revealed that herd generally consists of adult males, adult females, juveniles and calves. Adult females had maximum influence on the group size. The adult male gaurs are found to influence the group only through adult females. This follows the same pattern as in the case of American bison (Meagher, 1973) and European bison (Krasinski, 1978), where the bulls neither dominate nor lead the group even during the rutting period. Larter \& Gates (1994) observed similar pattern in the case of wood bison groups. This observation was supported by others (McHugh, 1958; Fuller, 1959). According to Spillett (1966) a population with more females than males generally has higher reproductive potential than the one that is predominantly composed of male. Our studyalso revealed same manners that population of female gaur is almost double of the male gaur, so it indicates that the populations of gaur at Kuldiha have a higher productive potential.

Over the year due to livelihood grazing, forest fire, scarcity of water, poacher and local tribal dependency on the forest for fire wood are the major conservational threats towards the gaur conservation. Awareness programme among local community, frontline forest staff and details study on gaur are inevitable for long term conservation and management of the species. 
Acknowledgements:

We owe our heartfelt gratitude to late Dr. Chandrasekhar Kar, former Senior Research Officer O/O PCCF Wildlife for his support and suggestion during our field study. We also thank the Vice Chancellor and the faculty members of North Orissa University for encouragement. We feel immense pleasure to thanking Divisional Forest Officers Mr. Kedar Swain and all the forests staffs of Kuldhia Wildlife Sanctuary for providing official necessity and kind supports during ourstudy periods.

\section{References:}

Champion H.G. \& Seth S.K. (1968): A revised survey of the forest types of India. Natraj Publication, New Delhi, 404 PP.

Choudhury A. (2002): Distribution and conservation of the Gaur Bos gaurus in the Indian Subcontinent. Mammal Review, 32(3): 199-226.

Daniel J.C., Desai A.A., Sivaganesan N. \& Rameshkumar S. (1987): The Study of Some Endangered Species of Wildlife and Their Habitats - the Asian elephant. Bombay Natural History Society, Bombay. 217pp.

Datta J.J, Belsare D.K. \& Chandiramani S.S. (1982): Status of the Gaur (Bos gaurus) in Kanha National Park, Madhya Pradesh. Proc. Symp. Ecol. Anim. Popul., Zoological Survey of India, 4:153-170.

Duckworth J.W., Steinmetz R., Timmins R.J., Pattanavibool A., Than Zaw, Do Tuoc \& Hedges, S. (20o8): Bos gaurus. The IUCN Red List of Threatened Species. Version 2015.2.www.iucnredlist.org Downloaded on 28 June 2015.

Fuller,W.A. (1959): The horns and teeth as indicators of age in bison.J. Wildl. Manage., 23:342-344.

Grubb, P. (2005): A Artiodactyla. In: Wilson, D. E. and D. M. Reeder (Eds.) Mammal species of the world. A taxonomic and Geographic References (3rd ed) pp 637-722. Johns Hopkins University Press, Baltimore, USA.

Krasinski Z.A. (1978) Dynamics and structure of the European bison population in the Bia ${ }^{3}$ owieza Primeval Forest. Acta Theriologica., 23:13-48.

Krause J. \& Ruxton G.D. (2002): Living in Groups. Oxford Series in Ecology \& Evolution, Oxford University Press, New York, 228 PP.

Krishnan M. (1972): An ecological survey of the larger mammals of Peninsular India. The Gaur. J. Bom. Nat. Hist. $\underline{\text { Soc. }} 69(2): 322-349$

Larter N.C. \& Gates C.C. (1994): Home range size of wood bison: effects of age, sex, and forage availability. J. Mammal., 75: 142-149.

McHugh T. (1958): Social behaviour of the American buffalo (Bison bison bison). Zoologica, 43: 1-41.

Meagher M. (1973): The Bison of Yellowstone National Park: Past and Present. National Park Service Scientific Monograph no. 1. Washington, D.C.: U.S. Government Printing Off ice.

Sankar K., Qureshi Q., Pasha M.K.S. \& Areendran G. (2001): Ecology of Gaur (Bos gaurus) in Pench Tiger Reserve, Madhya Pradesh. Final report, Wildlife Institute of India, Dehr Dun, 124pp

Schaller G.B. (1967): The Deer and the Tiger. Chicago University Press. Chicago. 370 PP.

Spillett J.J. (1966):The Kaziranga Wild Life Sanctuary, Assam. J. Bom. Nat. Hist. Soc., 63 (3): 494-528.

Stearns S.C. (1992): The Evolution of Life Histories. Oxford University Press, New York, 264 PP.

Sukumar R. (1989): The Asian Elephant: Ecology and Management. Cambridge University Press, Cambridge, UK. 